\title{
Carbon footprint of drinking water softening as determined by life cycle assessment
}

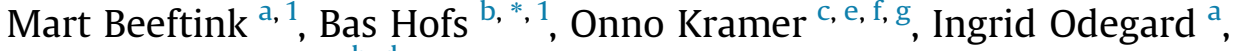 \\ Albert van der Wal ${ }^{\text {b, } d}$ \\ ${ }^{a}$ CE Delft, Oude Delft 180, 2611 HH, Delft, the Netherlands \\ b Department of Technology and Source Protection, Evides Water Company, P.O. Box 4472, 3006 AL, Rotterdam, the Netherlands \\ c Waternet, PO Box 94370, 1090 GJ, Amsterdam, the Netherlands \\ d Department of Environmental Technology, Wageningen University, Bornse Weilanden 9, 6708 WG, Wageningen, the Netherlands \\ e Delft University of Technology, Faculty of Civil Engineering and Geosciences, Department of Water Management, PO Box 5048,2600 GA, Delft, the \\ Netherlands \\ ${ }^{\mathrm{f}}$ Delft University of Technology, Faculty of Mechanical, Maritime and Materials Engineering, Department of Process and Energy, Leeghwaterstraat 39,2628 \\ $C B$, Delft, the Netherlands \\ ${ }^{\mathrm{g}} \mathrm{HU}$ University of Applied Sciences Utrecht, Institute for Life Science and Chemistry, PO Box 12011, 3501 AA, Utrecht, the Netherlands
}

\section{A R T I C L E I N F O}

\section{Article history:}

Received 6 April 2020

Received in revised form

22 July 2020

Accepted 23 August 2020

Available online 29 August 2020

Handling editor: Zhifu Mi

\section{Keywords:}

Attributional life cycle assessment

Softening

Carbon footprint

Drinking water

\begin{abstract}
A B S T R A C T
In the Netherlands, central softening of drinking water is widely applied for reasons of public health, client comfort, economic and environmental benefits. Currently, the detrimental contributions of softening, in particular the use of chemicals and energy, are taken into account in the carbon footprint of the Dutch drinking water companies. The beneficial contributions have, however, until now not been included in the carbon footprint. Here, we present an attributional life cycle assessment (LCA) for the softening of drinking water, including effects at the household level and several sensitivity analyses. Five central softening methods were included (pellet reactor (PR), water storage reservoir (WSR), reverse osmosis (RO), nanofiltration (NF) and ion exchange (IEX)). Domestic softening by IEX is represented as well. Central softening, except RO, is shown to reduce the carbon footprint when effects at the household level are included. The main detrimental contributions are caused by the consumption of chemicals and energy in the softening process. The main beneficial contributions of softened water with respect to the carbon footprint are at the household level. Decreases in water hardness result in reduced scaling and give rise to a prolonged lifespan of appliances in which water is heated, reduced energy use of those appliances and less required cleaning agents. For PR and WSR a new beneficial effect was identified; carbon capture in the crystallized calcite and dissolution of $\mathrm{CO}_{2}$ into the softened water. We show that for the Dutch water companies Evides and Waternet approximately 20\% and 60\%, respectively, of their total carbon footprint is compensated by the net carbon benefit of softening. The net total carbon footprint of drinking water softening in the Netherlands is estimated to be -0.11 Mtonne $\mathrm{CO}_{2}$ eq./yr.
\end{abstract}

(C) 2020 The Author(s). Published by Elsevier Ltd. This is an open access article under the CC BY license (http://creativecommons.org/licenses/by/4.0/).

\section{Introduction}

The hardness of drinking water is determined by the sum of the concentrations of $\mathrm{Ca}^{2+}$ (aq) and $\mathrm{Mg}^{2+}$ (aq) (GWRC, 2007). Softening

\footnotetext{
* Corresponding author.

E-mail addresses: beeftink@ce.nl (M. Beeftink),b.hofs@evides.nl, bashofs@ gmail.com (B. Hofs), onno.kramer@waternet.nl, o.j.i.kramer@tudelft.nl (O. Kramer), odegard@cedelft.nl (I. Odegard), B.vanderwal@evides.nl (A. van der Wal).

1 Shared first authorship.
}

is the process of reducing the hardness of drinking water. The main advantages of softening of 'hard' drinking water are decreases in; (i) the solubility of lead and copper, (ii) the amount of cleaning agents that need to be used, (iii) scaling by calcium carbonate in appliances that heat water, leading to an experienced increased level of comfort by consumers (van den Hoven and van Eekeren, 1988; GWRC, 2007; van der Bruggen et al., 2009; Abeliotis et al., 2015).

Central softening of drinking water is currently (partly) applied in several countries (e.g. the Netherlands, Belgium, Germany, France and the USA) and domestic softening is the most applied way of softening in other countries (GWRC, 2007). Due to concerns 
about a possible relation between hardness and cardiovascular diseases, large scale application of central softening in the Netherlands was at first limited (Graveland et al., 1983). In 1982, however, it was concluded that softening of drinking water down to $1.5 \mathrm{mmol} \mathrm{Ca} / \mathrm{L}$ would not result in adverse health effects (Graveland et al., 1983) and the World Health Organization (WHO) currently has no guideline value for hardness of drinking water (WHO, 2017). Since 1982, central softening has been applied to nearly all drinking water that can benefit from softening in the Netherlands (Hofman et al., 2007). Currently, legislation in the Netherlands allows central softening down to a total hardness of $1.0 \mathrm{mmol} / \mathrm{L}$ (Drinkwaterbesluit, 2018). The pellet reactor (PR, see Table 1 for all used acronyms) is the most applied central softening process for drinking water production. In a PR calcite is crystallized onto pellets and seeding material in liquid-solid fluidized bed reactors by addition of a strong base like for example sodium hydroxide (Hofman et al., 2007). Other processes that are sometimes used for softening are ion exchange (IEX), nanofiltration (NF) and reverse osmosis (RO). In IEX $\mathrm{Ca}^{2+}(\mathrm{aq})$ is removed from the water by exchange for either $2 \mathrm{H}^{+}$or $2 \mathrm{Na}^{+}$from the IEX resin. NF and RO reduce hardness by filtration of water under pressure through membranes with very small pores. In a few locations, softening of drinking water is achieved in a water storage reservoir (WSR) by addition of a base to the reservoir. Softening at household level is usually achieved through IEX (GWRC, 2007; van der Bruggen et al., 2009; Tang et al., 2019).

The environmental impact of softening can be determined with a life cycle assessment (LCA). Some LCA studies on softening have been done, but they are usually confined to effects within the water treatment (Sombekke et al., 1997; Mohapatra et al., 2002; Barrios et al., 2008; Tapia et al., 2008) or consider only limited effects elsewhere, like for example the effect of replacement of calcite as a natural resource by calcite pellets (Schetters et al., 2015). Only a few studies are available that include effects at the consumers' homes, and these show a beneficial environmental impact when these effects are considered (Regueira, 2000; Hofman et al., 2007; Godskesen et al., 2012; Mulder, 2014). To our knowledge, no LCA has been done which addresses impacts both at the water treatment site and at the consumer level for different types of softening methods, including a home softening method.

The Dutch drinking water companies have the ambition to be climate neutral well before the European Union's current goal of 2050 (van der Hoek et al., 2017). Currently, the Dutch drinking water companies determine the carbon footprint (CF) of their activities (Greenhouse Gas (GHG) protocol, scope 1, 2 and 3), which includes the chemicals and raw materials (e.g. seeding material) used in the softening process. The environmental benefits of central

\section{Table 1}

List of acronyms.

\begin{tabular}{ll}
\hline LCI & Life Cycle Inventory \\
\hline LCA & Life Cycle Assessment, \\
GWP & Global Warming Potential, \\
GTP & Groundwater Treatment Plant, \\
CF & Carbon Footprint, \\
PR & Pellet Reactor \\
WSR & Water Storage Reservoir, \\
RO & Reverse Osmosis, \\
NF & Nanofiltration, \\
IEX & Ion Exchange \\
DS & (Decentralized) Domestic Softener \\
SD & Supplementary Documentation, \\
WBB & Waterwinningbedrijf Brabantse Biesbosch, \\
WTP & Water Treatment Plant \\
WWTP & Waste Water Treatment Plant \\
COD & Chemical Oxygen Demand \\
\hline
\end{tabular}

softening at consumer level has, however, never been fully calculated for the Netherlands and is therefore not yet present in the $\mathrm{CF}$ calculations of the Dutch drinking water companies.

\section{Methodology}

\subsection{Goal and scope definition}

\subsubsection{Goal}

The aim of the analysis is to address the limited available information about the CF of the five central and one decentral softening methods (PR, WSR, RO, NF, IEX and DS). We determine the change in $\mathrm{CF}$ when a decentralized domestic softener is used at home and when centralised softening is added to the water treatment plant, using a LCA approach (attributional). The hotspots are identified and recommendations are given to both drinking water companies and consumers on how to reduce their carbon footprint.

\subsubsection{Functional unit}

The functional unit of this study is the softening of $43 \mathrm{~m}^{3}$ drinking water. This is the average water usage per person per year in the Netherlands (VEWIN, 2019) and is a bit below the European average of $53 \mathrm{~m}^{3}$ (EEA, 2018). For data on the average water consumption and the effects of softened drinking water in households in this study (Section 3.4) we assume a person living in a twoperson household. In this analysis, we calculate the change of $\mathrm{CF}$ for the following two scenarios:

- Central softening: five central softening methods are analysed for softening of water from $2.4 \mathrm{mmol} / \mathrm{L}$ to $1.4 \mathrm{mmol} / \mathrm{L}$.

- Decentral softening: one decentral softening method is analysed for softening of water from $2.4 \mathrm{mmol} / \mathrm{L}$ to $0.0 \mathrm{mmol} / \mathrm{L}$.

The reference situation of $2.4 \mathrm{mmol} / \mathrm{L}$ is selected, as this is a commonly found hardness of water sources in the Netherlands before softening is applied (Siegers, 2002). The results presented reflect the environmental benefits and burdens relative to the reference situation.

\subsubsection{Geographical and temporal scope}

Even though the Netherlands is used as a case study in this analysis, it can be assumed that the performed analysis is also applicable to similar softening processes in other countries with an appropriate level of economy and technical development. The effects are not specific for the Netherlands. Naturally, the CF of softening depends on the softening depth. Most of the data provided in the Life Cycle Inventory (LCI) can be assumed to have a positive linear relation to the softening depth. This is not always the case, especially around a hardness of $1.0 \mathrm{mmol} / \mathrm{L}$ (Godskesen et al., 2012). Therefore, one should be attentive when interpreting the results for other countries with different softening depths. Furthermore, we estimate that results of this analysis are valid for the period between 2018 and 2025, and for regions with a similar production processes for auxiliaries and electricity. After 2025, the results should be updated as the GWP of electricity and auxiliaries will likely change.

\subsubsection{System definition and boundaries}

The drinking water softening affects the $\mathrm{CF}$ of different processes. In this analysis, the following effects/processes (including transport) are taken into account (see also Fig. 1):

- The energy, chemicals and raw materials required for the softening process

- The materials and the basic manufacturing steps required to produce the softening installations 


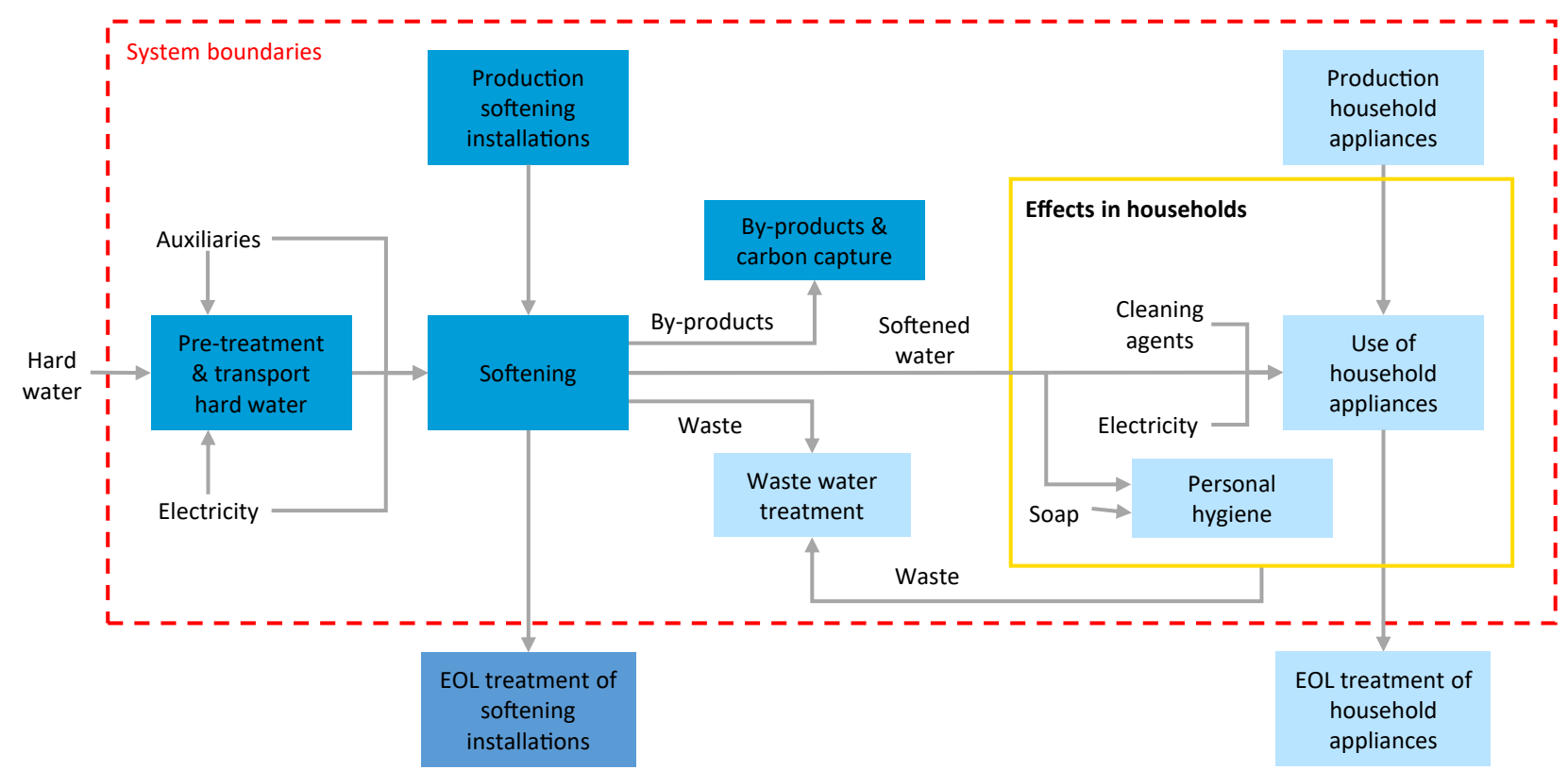

Fig. 1. Chosen system boundaries for both the central and decentral softening methods.

- The increased need for pre-treatment and transport of hard water due to water losses during the softening process

- The production of by-product (calcite pellets) which can be used to replace other products.

- The carbon capture due to the production of the by-product

- The effects in households:

o Influence of limescale on lifetime and energy use of household appliances

o Influence of hardness on use of cleaning agents

- The treatment of waste water, including the change in amount of cleaning agents present in the waste water of households

Recycling of the softening installations and household appliances are not taken into account as the environmental benefits of recycling (avoiding new material production) in 20-40 years is very uncertain.

\subsection{Allocation}

No allocation is applied in this study. The CF of the softening step (Fig. 1) is fully allocated to the softening of water, even though the $\mathrm{RO}$ and NF softening installations are also used simultaneously for other purposes, such as improving the water quality by removing other undesired components from the water (Hoslett et al., 2018).

\subsection{Data collection \& quality}

The scenarios are modelled in the SimaPro 9.1 LCA software. The CF is calculated using the IPCC 2013 GWP 100a V1.03 methodology. The foreground data in this study is based on the following sources (in decreasing order of preference): process specific data collected at water treatment plants, calculations using specialized software, literature, expert judgements and other publicly available data. The Ecoinvent v3.6 LCA-database (which includes transportation) is used for most background processes such as building materials, electricity and auxiliaries, except when other available sources on the GWP of products are deemed more accurate.

The inventory data used to model the softening process and the pre-treatment of hard water is considered to be of high quality, as most of the data is either based on measurement from water treatment plants, process specific literature or calculated by experts using specialized software. The PR data is based on measurements of groundwater treatment plant (GTP) Baanhoek in 2018 (Evides, 2019), calculations for GTP Haamstede en Ouddorp using projection software AquaCalc (de Ridder et al., 2019), and data (HofmanCaris et al., 2016). WSR data is based on measurements from Petrusplaat, one of the WSRs of 'Waterwinningbedrijf Brabantse Biesbosch' (WBB) (2013-2018) (Evides, 2019). RO is based on Hofman-Caris et al. (2016). Data for NF and IEX are based on (Bonton et al., 2012) and calculations with the projection software WAVE (de Ridder et al., 2019). DS is based on public information (AquaCell, 2019) on existing domestic softeners.

The literature data on the effect of drinking water softening at households has a higher uncertainty as the influence of the hardness of water in appliances and consumer behaviour depends on the chosen degree of softening and is difficult to measure accurately. Only one study could be found which was able to provide reliable data (Godskesen et al., 2012). The carbon capture in calcite pellets has a high uncertainty as it depends on the exact amount of $\mathrm{CO}_{2}$ that dissolves from air into the softened water after softening, and this amount has never been accurately determined. The data concerning the production of the softening installations and waste water treatment are based on expert knowledge, as these processes are expected to have a relatively small (and in most cases negligible) CF. The effects of the uncertainties deemed to influence the results most significantly are addressed in the sensitivity analysis in Section 4.2.

In this paper, the key assumptions are explained in more detail and the most relevant sources are displayed. In order to encourage other researchers, companies and LCA experts to reproduce, update or adjust our findings, the supplementary documentation (SD) provides detailed information on other assumptions (mainly about the chosen inventory data), data sources, process schemes and the used inventory processes (mostly from the Ecoinvent database).

\section{Life cycle inventory}

\subsection{Pre-treatment and transport of hard water}

For all softening methods, with the exception of WSR, the water treatment facility is assumed to have the following processes in 
place: aeration, coagulation, (pre)filtration, infiltration, abstraction of water, rapid sand filtration, biological activated carbon filtration and UV disinfection. The WSR only contains the abstraction and aeration processes.

We define the pre-treatment as all processing steps that occur before the actual softening process. As different softening techniques are used at different locations in the treatment facility, the amount of energy and chemicals used in the pre-treatment can differ per softening method.

The required chemicals were gathered for each processing step together with the total electricity demand of the pre-treatment steps. As can be seen in Table 2, the pre-treatment for the WSR requires no auxiliaries and only a small amount of electricity compared to the other softening methods.

The change in CF during pre-treatment when adding softening is calculated using the inventory data and the effect that the water losses during softening (Section 3.2) have on the amount of chemicals and energy used during the pre-treatment steps. In the sensitivity analysis we also calculate the change in CF when a less extensive pre-treatment, containing only the aeration, coagulation and (pre)filtration steps, is used.

\subsection{Softening process}

\subsubsection{Inventory of water losses, electricity use and auxiliaries}

The inventory data (water losses, electricity usage and required auxiliaries) of all softening techniques are shown in Table 3. The water losses caused by softening affect both the CF of the pretreatment steps (Section 3.1) and the waste water treatment (Section 3.5). The environmental benefits of the calcite co-product created in PR and WSR are explained in Section 3.2.2.

Most data on softening is provided for different degrees of softening. Similar to Godskesen et al. (2012) and van der Bruggen et al. (2009), it is assumed that the required electricity and auxiliaries (except membranes) and produced co-products have a positive linear correlation to the softening depth.

In the WSR, the softening chemical is added to the water by unloading a truck directly into the WSR. As a result mixing is not as good as in the controlled environment of a PR, which has a fluidized bed which facilitates crystallization that is not present in the WSR. Therefore, softening in a WSR requires more base per mmol softening than the PR. The water losses at the WSR are caused by evaporation and seep. For softening in a WSR, one could also take into account losses in subsequent drinking water treatment, as these effectively lower the amount of drinking water produced. As these losses are low for Evides (2\%), these were not taken into account. RO and NF have the highest water losses and require the most electricity. DS also uses ion-exchange (IEX) for softening and requires more salt than IEX due to the larger softening depth of $2.4 \mathrm{mmol} / \mathrm{L}$ instead of $1.0 \mathrm{mmol} / \mathrm{L}$. DS loses more water than IEX due to the smaller scale.

\subsubsection{Carbon capture due to production of calcite}

Softening in a PR and WSR is achieved by crystallization into calcite in fluidized bed reactors (see Equation (1)) (Graveland et al., 1983; Dits, 1995).

$\mathrm{Ca}^{2+}+2 \mathrm{HCO}_{3}^{-}+\mathrm{NaOH} \rightarrow \mathrm{CaCO}_{3}+\mathrm{Na}^{+}+\mathrm{HCO}_{3}^{-}+\mathrm{H}_{2} \mathrm{O}$

Such production of calcite in a PR or WSR has two potential environmental benefits. First of all, the calcite can be used in many long-lasting applications, such as concrete, filler and carpets (AquaMinerals, 2019). According to a confidential LCA performed by AquaMinerals, this replacement of conventional materials has a small environmental benefit of $-14.5 \mathrm{~kg} \mathrm{CO}$ eq. per tonne calcite. The calcite produced in the WSR does not replace conventional materials as it is stored in the WSR and will likely remain there for more than a century. Secondly, as $\mathrm{CO}_{3}^{2-}, \mathrm{HCO}_{3}^{-}$and $\mathrm{H}_{2} \mathrm{CO}_{3}$ in water are in constant exchange with $\mathrm{CO}_{2}$ in the air, the removal of $\mathrm{HCO}_{3}^{-}$ from water ultimately increases the $\mathrm{CO}_{2}$-uptake from the air. An extreme version of PR has even been proposed as an efficient process to capture $\mathrm{CO}_{2}$ from air (Burhenne et al., 2017). We take this $\mathrm{CO}_{2}$-uptake into account as the exchange happens on relatively short time scales compared to the effects of global warming.

The maximum theoretical amount of $\mathrm{CO}_{2}$ that can be captured, based on the molecular formula, is 0.44 tonne $\mathrm{CO}_{2}$ per tonne of produced calcite. To determine the minimum impact of softening by PR and WSR on climate change, the amount of $\mathrm{CO}_{2}$ taken up from the atmosphere by the ocean is used as a benchmark. About $31 \%$ of all anthropogenic $\mathrm{CO}_{2}$ has been taken up from the atmosphere by the oceans (Gruber et al., 1996, 2019). The uptake of $\mathrm{CO}_{2}$ by the oceans is not uniform (Wooley et al., 2015; Gruber et al., 2019); in the North Atlantic Ocean the $\mathrm{CO}_{2}$ uptake can be almost a factor two above the average, up to about 57\% (Gruber et al., 2019). Again, this shows that $\mathrm{CO}_{2}$ is only partly taken up by water and that the amount is uncertain.

Table 2

Inventory data of pre-treatment steps for each softening method.

\begin{tabular}{|c|c|c|c|}
\hline Pre-treatment & $\begin{array}{l}\text { Softening } \\
\text { method }\end{array}$ & Amount & Sources/assumptions \\
\hline \multirow[t]{4}{*}{ Electricity $\left(\mathrm{kWh} / \mathrm{m}^{3}\right)$} & RO, NF, IEX & 0.60 & $\begin{array}{l}\text { Based on the average electricity consumption of WTP Leiduin and WTP Ouddorp in the Netherlands, assuming 50\% usage } \\
\text { for office space. }\end{array}$ \\
\hline & PR & 0.54 & $\begin{array}{l}\text { Softening with PR occurs before aeration, biological activated carbon filtration and UV disinfection. Using the energy } \\
\text { consumption of these processes reported in Hofman-Caris et al. (2016), electricity usage of the pre-treatment is assumed } \\
\text { to be } 90 \% \text { of } 0,60 \mathrm{kWh} / \mathrm{m}^{3} \text {. }\end{array}$ \\
\hline & DS & 0.70 & $\begin{array}{l}\text { As the DS softens the water at the consumer, water losses also affect the electricity usage required for distributing the } \\
\text { water. According to (Evides, 2019), the average electricity required for distribution is } 0,10 \mathrm{kWh} / \mathrm{m}^{3} \text {. }\end{array}$ \\
\hline & WSR & 0.084 & Data from the WBB in the Netherlands. \\
\hline \multirow[t]{2}{*}{$\mathrm{NaOCl}\left(\mathrm{g} / \mathrm{m}^{3}\right)$} & $\begin{array}{l}\text { PR, RO, NF, } \\
\text { IEX, DS }\end{array}$ & 0.275 & \\
\hline & WSR & - & \\
\hline \multirow[t]{2}{*}{$\mathrm{FeCl}_{3}\left(\mathrm{~g} / \mathrm{m}^{3}\right)$} & $\begin{array}{l}\text { PR, RO, NF, } \\
\text { IEX, DS }\end{array}$ & 4.72 & \\
\hline & WSR & - & \\
\hline \multirow[t]{2}{*}{$\begin{array}{l}\text { Granular activated } \\
\quad \text { carbon }\left(\mathrm{g} / \mathrm{m}^{3}\right)\end{array}$} & $\begin{array}{l}\text { RO, NF, IEX, } \\
\text { DS }\end{array}$ & 17 & \\
\hline & PR, WSR & - & Softening with PR occurs before biological activated carbon filtration. \\
\hline
\end{tabular}

Source: Three water treatment plants in the Netherlands using PR and one using WSR (Evides, 2019). 
Table 3

Inventory data of all softening techniques when reducing the hardness of $1 \mathrm{~m}^{3}$ water by $1,0 \mathrm{mmol} / \mathrm{L}$.

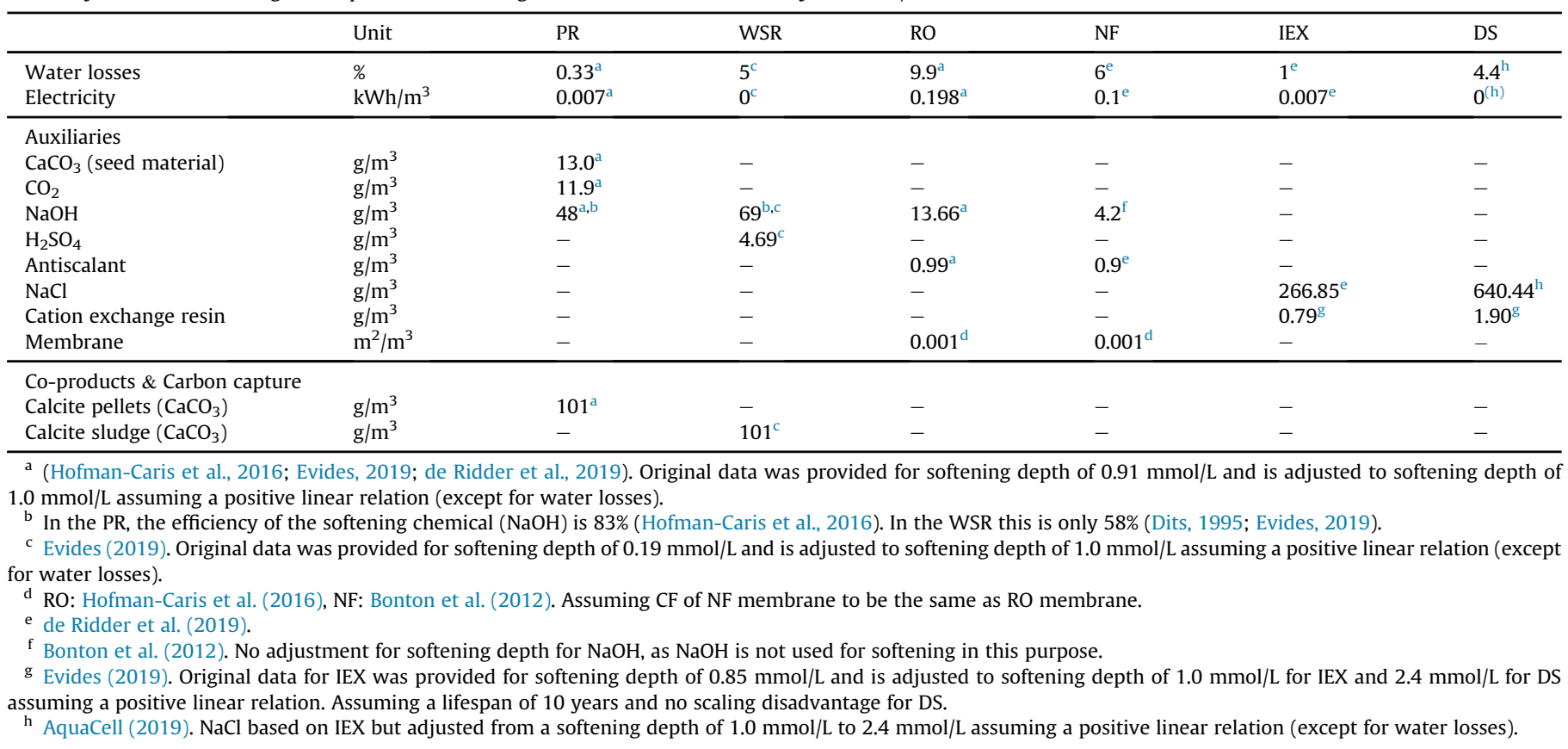

The softening in the WSR Petrusplaat removes $0.56 \mathrm{mmol} / \mathrm{L}$ $\mathrm{CO}_{3}^{2-}$ (aq) from the raw water, but the sum of $\mathrm{HCO}_{3}^{-}(\mathrm{aq})$ and $\mathrm{CO}_{3}^{2-}(\mathrm{aq})$ at the outlet is only $0.28 \mathrm{mmol} / \mathrm{L}$ lower (based on some 300 measurements of $\mathrm{HCO}_{3}^{-}$and $\mathrm{CO}_{3}^{2-}$ in the period 2014-2018). Apparently, in the WSR $0.28 \mathrm{mmol} / \mathrm{L} \mathrm{CO}_{2}$, which is $50 \%$ of the removed $\mathrm{CO}_{3}^{2-}$, is taken up from the atmosphere and reacts into either $\mathrm{HCO}_{3}^{-}(\mathrm{aq})$ or $\mathrm{CO}_{3}^{2-}(\mathrm{aq})$. This takes place in 25 days; the average residence time of the well-mixed (by aeration and wind) water in the WSR Petrusplaat. As biological processes probably also play a role in the carbon cycle of the WSR, not all the $\mathrm{CO}_{2}$ uptake is necessarily due to softening. However, as the changes in $\mathrm{HCO}_{3}^{-}(\mathrm{aq})$ and $\mathrm{CO}_{3}^{2-}(\mathrm{aq})$ at two WSR without softening at the same location are significantly smaller, it appears that most of the effect in the Petrusplaat is due to softening.

Ultimately, we are unable to exactly determine the CF storage of $\mathrm{CO}_{2}$ in the form of calcite. The value lies between approximately $31 \%$ of uptake in the oceans and the $100 \%$ of 0.44 tonne $\mathrm{CO}_{2}$ per tonne produced calcite. We chose to set the environmental benefit of precipitation in softening at 0.20 tonne $\mathrm{CO}_{2}$ per tonne of produced calcite, $45 \%$ of the maximum value and close to the $50 \%$ observed over the WSR Petrusplaat.

\subsection{Production of softening installations}

Table 4 shows a rough estimate of the building materials required for the production of the softening installations.

Only data on the amount of steel, concrete and plastics were collected as these are the main materials that are used. It is assumed that the galvanized steel and plastics are further processed into the desired shape using impact extrusion and thermoforming, respectively. The WSR does not contain a softening installation and therefore requires no building materials. As no information could be found on the building materials required for $\mathrm{RO}$, the required materials are assumed to be equal to NF.

\subsection{Effects of the softened drinking water in households}

According to (Godskesen et al., 2012), hard water has three main consequences when used in households. Firstly, hard water shortens the service life of household appliances which heat water due to an increased amount of limescale present on their heating elements (Godskesen et al., 2012; van der Bruggen et al., 2009). As a result, more household appliances must be produced. Secondly, household appliances consume more energy because of limescale. Finally, more cleaning agents are used for the removal of limescale and more soap for personal hygiene.

Losses of drinking water due to leakage in the distribution system were not taken into account in the calculation of the $\mathrm{CF}$ at consumers households here. These are low (5\%) in the Netherlands (VEWIN, 2019), but can be substantial in other countries.

\subsubsection{Decreasing electricity usage and prolonging lifespan of household appliances}

According to van der Bruggen et al. (2009), when the water hardness is $<1.5 \mathrm{mmol} / \mathrm{L}$, the amount of limescale deposit in household appliances is negligible. When the hardness is $>1.5 \mathrm{mmol} / \mathrm{L}$, every $3.0 \mathrm{mmol} / \mathrm{L}$ increase in hardness is expected to cause an average increase of $1.0 \mathrm{~mm}$ limescale during the entire lifespan of the appliance (van der Bruggen et al., 2009).

When less limescale deposit is present the electricity usage of household appliances with heating elements decreases while the

Table 4

Estimated building materials for the production of the softening installations.

\begin{tabular}{llllll}
\hline Production & Unit & $\mathrm{PR}^{\mathrm{a}}$ & $\mathrm{NF}(\& \mathrm{RO})^{\mathrm{b}}$ & $\mathrm{IEX}^{\mathrm{a}}$ & $\mathrm{DS}^{\mathrm{c}}$ \\
\hline Production per year & $\mathrm{Mm}^{3}$ & 4 & 0.73 & 4 & $8.6 \times 10^{-5}$ \\
Lifespan & $\mathrm{y}$ & 40 & 20 & 40 & 20 \\
Total production & $\mathrm{Mm}^{3}$ & 160 & 14.6 & 160 & $1.72 \times 10^{-3}$ \\
Building materials per & $\mathrm{m}^{3} \mathrm{produce}^{2}$ drinking water & & \\
Galvanized steel & $\mathrm{g} / \mathrm{m}^{3}$ & 0.09 & 0.72 & 0.05 & 9.88 \\
Concrete & $\mathrm{g} / \mathrm{m}^{3}$ & 0.44 & 1.50 & 0.24 & - \\
Plastics & $\mathrm{g} / \mathrm{m}^{3}$ & - & 0.24 & - & 1.74 \\
$\quad$ Total & $\mathrm{g} / \mathrm{m}^{3}$ & 0.53 & 2.46 & 0.29 & 11.63 \\
\hline
\end{tabular}

a Source: RHDHV (2019).

b Source: Bonton et al. (2012), adjusted lifespan from 10 years to 20 years.

c Estimated by authors, based on total weight $(20 \mathrm{~kg})$ of a commercial DS and the average water usage of a two-person household. 
expected lifespan increases. Similar to Godskesen et al. (2012), the domestic appliances affected by the softened water were identified as washing machines, coffee machines, kettles and dishwashers. Godskesen et al. (2012) determined the electricity usage and lifespan of household appliances based on hardness of $3.62 \mathrm{mmol} / \mathrm{L}$, $2.54 \mathrm{mmol} / \mathrm{L}$ and $1.45 \mathrm{mmol} / \mathrm{L}$. For central heating systems, boilers and scaling in hot water pipes no data on the effect of scaling could be found. Thus, any potential energy-saving effect and lifespan increase due to softening could not be taken into account.

The data provided by Godskesen et al. (2012), is adjusted to the water hardness in our two scenarios in two steps. First, we interpolate the data to obtain the data for $2.4 \mathrm{mmol} / \mathrm{L}$. Secondly, as we argued that with a hardness of $<1.5 \mathrm{mmol} / \mathrm{L}$ the amount of limescale deposit is negligible, the electricity consumption and lifespan of the household appliances for $1.4 \mathrm{mmol} / \mathrm{L}$ and $0.0 \mathrm{mmol} / \mathrm{L}$ are set to the same values presented by Godskesen et al. (2012), at $1.45 \mathrm{mmol} / \mathrm{L}$.

For the calculation of the CF of the appliances, it is assumed that an average two-persons household contains 0.99 washing machines, 0.75 dishwashers (VEWIN, 2017), 1 coffee machine and 1 kettle (Godskesen et al., 2012).

\subsubsection{Less cleaning agents required}

Calcium ions interact with cleaning agents such as laundry detergent, soap, acetic acid and softening salt for the dishwasher. Therefore, when water is softened, less cleaning agents are required to obtain the same washing result (Godskesen et al., 2012; Hofman et al., 2007). Similar to Godskesen et al. (2012) it is assumed that there is a linear correlation between water hardness and the required amount of cleaning agents.

In the Netherlands, the average person uses $7 \mathrm{~kg}$ laundry detergent per year (Bisschops and Zeeman, 2018). WQRF (2011) tested the amount with which the usage of laundry detergent could be reduced when softer water is used, without negatively affecting the washing results. They concluded that for a hardness of $5.12 \mathrm{mmol} / \mathrm{L}, 100 \%$ of the recommended quantity is required, whereas with $2.57 \mathrm{mmol} / \mathrm{L}$ only $75 \%$ and with $0.0 \mathrm{mmol} / \mathrm{L}$ only $50 \%$ is required. Based on these results we estimate that when the hardness is reduced from $2.4 \mathrm{mmol} / \mathrm{L}$ to $1.4 \mathrm{mmol} / \mathrm{L}, 12.5 \%$ less detergent is required, and when further reducing the hardness from $2.4 \mathrm{mmol} / \mathrm{L}$ to $0.0 \mathrm{mmol} / \mathrm{L}, 30 \%$ less detergent is required.

The potential reduction in use of soap, acetic acid and softening salt in the Netherlands is estimated using the data from Godskesen et al. (2012). The data is adjusted in the same manner as described in Section 3.4.1 (see SD).

Some people will keep using the same quantities of cleaning agents, even if it is not necessary anymore. According to Mulder (2014), at most $25 \%$ of the consumers are likely to use less cleaning agents right away after central softening is applied. As it is expected that more consumers will adapt their behaviour over time, we estimate that on average $25 \%$ of the consumers will use less cleaning agents. For decentral softening we assume this to be $50 \%$, as such a purchase is likely to increase the consumers' knowledge about the benefits of soft water and willingness to adapt their behaviour. In the sensitivity analysis, the results are calculated for different consumer adaption behaviours.

\subsection{Waste water treatment}

The carbon footprint of a waste water treatment plant (WWTP) is mostly determined by direct emissions of greenhouse gasses, the amount of electricity and chemicals required for the removal of Chemical Oxygen Demand (COD), sludge treatment and transport, and by the transportation of water (see for example Sabeen et al. (2018) and references therein).
The waste water from the softening installation mostly contains salts (removed by RO or NF or added for regeneration by IEX or DS) and a small amount of antiscalant (RO, NF). This means direct emissions of GHG are not an issue. Furthermore, according to Waternet (2019), the WWTP of Waternet does not treat salts, the CF of treating the small amount of antiscalant and resulting sludge is negligible. The amount of waste water that has to be transported because of the water losses (see Table 3 ) is taken into account with an average electricity usage of $0.036 \mathrm{kWh} / \mathrm{m}^{3}$ (Waternet, 2019).

The waste water in households will contain less cleaning agents when softening is applied. The COD of the cleaning agents are based on literature and our own calculation (see SI). The removal of COD requires $0.33 \mathrm{kWh}$ of electricity per $\mathrm{kg}$ COD, whereas the amount of chemicals required for COD removal is negligible (Waternet, 2019).

\section{Results and discussion}

\subsection{LCA results}

In Fig. 2 the CF of the five central and one decentral softening methods including effects at the household level are presented in $\mathrm{kg} \mathrm{CO}$ eq. per person per year. The contribution of different aspects is shown; adverse processes have a $\mathrm{CF}>0$, beneficial processes a $\mathrm{CF}<0$. The overall $\mathrm{CF}$ of softening is given by the white diamond. Fig. 2 shows that the net $\mathrm{CF}$ of central softening of drinking water is negative (environmentally beneficial), except in the case of RO. As mentioned in Section 2.2, we allocate the full impact of RO and NF to softening, even though the RO and NF softening installations are also used simultaneously for other purposes. As a consequence, the $\mathrm{CF}$ of the softening process presented for RO an NF can be considered to be an upper limit, which would be lower if allocation would have been applied. The CF of DS is the highest and has a net environmental cost.

The (environmentally) adverse impacts (shown above 0) are divided into four categories. The main adverse impact (65-99\% for all methods), consisting of the required chemicals and energy, is shown as a blue bar for all methods. The smaller light blue bars give the $\mathrm{CF}$ related to additional need for pre-treatment due to water losses. For RO and NF this contribution is relatively large and accounts for about $25 \%$ of the total harmful impact. The CF of waste treatment is given in grey and is below $2 \%$ of the total for all softening methods. Finally, the impact of the production of the installations is shown in green. As expected this is largest for decentral softening, as far more materials are needed for building many small installations than for several large central ones.

Fig. 2 also shows the (environmentally) beneficial impacts (shown below 0 ) of softening, which again are divided into four categories. The mint green bars give the effect of a lower energy use of household appliances due to thinner limescale deposits. This effect is the same for all processes, as below a hardness of about $1.5 \mathrm{mmol} / \mathrm{L}$ the amount of deposit is negligible (van der Bruggen et al., 2009). The impact of prolonged lifespan of appliances, shown by the orange bar, is also the same for all processes, for the same reason. The purple bar gives the impact of a decrease in the required amount of cleaning agents. This effect is the same for the central techniques but is about five times higher for the decentral method (DS). This is because (i) we assumed that $50 \%$ of the owners of a DS use the correct lower dosage as opposed to only $25 \%$ in case of central softening and (ii) because softening to below a hardness of $1.4 \mathrm{mmol} / \mathrm{L}$ does decrease the required amount of cleaning agents. Finally, in the case of PR and WSR the yellow bar gives the impact due to carbon capture in water and calcite by-products. This last contribution has not been taken into account in an LCA for softening before and here it is shown to be a relevant benefit for PR and WSR. 


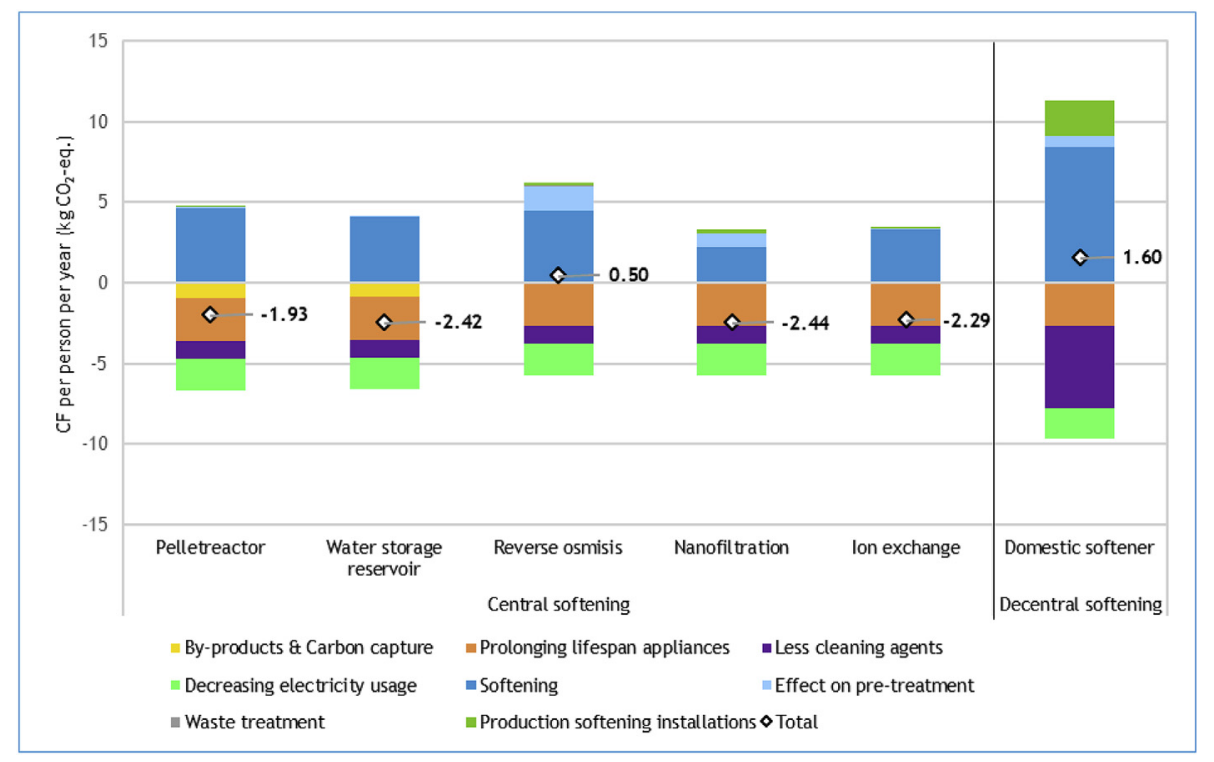

Fig. 2. CF of five central softening and one decentral softening methods.

Note: The domestic softener softens the water from $2.4 \mathrm{mmol} / \mathrm{L}$ to $0.0 \mathrm{mmol} / \mathrm{L}$ instead of $1.4 \mathrm{mmol} / \mathrm{L}$ (see Section 2.1 .2 ).

\subsection{Sensitivity analysis}

Sensitivity analyses were done for (i) the effect of extensive or limited pre-treatment, (ii) carbon capture in water and calcite byproducts, (iii) the $\mathrm{CO}_{2}$ footprint of the used $\mathrm{NaOH}$, (iv) the $\mathrm{CF}$ of the production of softening installations, ( $v$ ) the percentage of consumers using the correct amount of cleaning agents, and (vi) the electricity production. The most important findings are discussed in this section (see SD for all results).

Extensive and limited pre-treatment represents the treatments for raw water from surface water or groundwater, respectively. For PR, WSR and IEX the effect of having extensive pre-treatment instead of limited pre-treatment on the CF is minor, as a (relatively) small amount of water is lost in these processes. The CF of RO and NF, however, decrease by 1.1 and $0.6 \mathrm{~kg} \mathrm{CO}_{2}$ eq., respectively, as significantly larger percentages of water are lost as concentrate. For DS the CF decreases by 0.45 .

The amount of $\mathrm{CO}_{2}$ which is actually absorbed (somewhere between 0 and $100 \%$ of the max potential) in the softened water (called: 'carbon capture') has a large effect on the CF of the PR and WSR. In the base scenario $45 \%$ absorption was chosen. At $0 \%$ adsorption the total CF of PR and WSR would increase by $0.9 \mathrm{~kg} \mathrm{CO}$ eq. As a result, NF and IEX would have the lowest CF. At $100 \%$ adsorption the CF of PR and WSR would decrease by $1.1 \mathrm{~kg} \mathrm{CO}_{2}$ eq. As a result, PR and WSR would have the lowest CF.

Another factor in the LCA which is subject to variation is the $\mathrm{CF}$ of $\mathrm{NaOH}$. The value from the most recent Ecoinvent database has been used here, but the supplier gives a considerably lower footprint, whereas drinking water companies (such as Waternet) have used a higher value in the calculations of their carbon footprint in the past (as the value in the database used to be higher). The information from the supplier is specific and probably most up to date, but the underlying LCA cannot be found in the public domain. PR and WSR are most sensitive to this parameter, as the use of $\mathrm{NaOH}$ is the largest contributor to their CF. If the CF of $\mathrm{NaOH}$ is as high as used by Waternet in the past, NF and IEX have the lowest CF. If it is as low as given by the supplier however, PR and WSR have the lowest $\mathrm{CF}$.
Considering that some capital goods are excluded and only basic manufacturing processes are taken into account (see Section 2.3 and 3.3), the CFs for the production of softening installation are conservative. If the $\mathrm{CF}$ of production would double when including all capital goods and related manufacturing processes, the total CF for DS would increase significantly (2.41 $\mathrm{kg} \mathrm{CO}_{2}$ eq.), while the total $\mathrm{CF}$ of centralized softeners will increase only slightly (max $0.18 \mathrm{~kg}$ $\mathrm{CO}_{2}$ eq.). Therefore, it can be concluded that the $\mathrm{CF}$ for the production of DS is conservative, as is the difference in CF between the centralized softeners and decentralized softener.

The largest possible decrease in the CF of softening is given by the potential reduction in the amount of used cleaning agents. The actual reduction in the amount depends on the adaptation of households (between 0 and 100\%). When the adaptation increases from 0 to $100 \%$, the CF of centralized and decentralized softeners decreases by 4.4 and $10.1 \mathrm{~kg} \mathrm{CO}$ eq. per person per year, respectively. Fig. 3 shows the effect of an increasing percentage of consumers who lower the amount of used cleaning agents, for PR. For the other centralized softening methods the changes in the $\mathrm{CF}$ are the same $(-1.09 \mathrm{~kg} \mathrm{CO}$-eq per additional $25 \%$ of consumer adaptation) and can be calculated from Fig. 2. For example, when $75 \%$ of the consumers reduce their use of cleaning agents, the CF of softening in a WSR becomes $-2.42+(2 *-1.09)=-4.60 \mathrm{~kg} \mathrm{CO}$-eq per person per year. Even though the decentralized softener (DS) has a larger potential benefit $(-2.53 \mathrm{~kg} \mathrm{CO}$-eq per additional $25 \%$ of consumer adaptation), the CF remains higher in all scenarios - except $100 \%$ adaptation where DS passes RO in obtained benefit.

Finally, the CFs are evaluated for a different electricity mix: 100\% renewable. In the base scenario the $\mathrm{CF}$ of the average Dutch electricity mix is used. The CF of NF and RO decreases the most (2.0 and $3.9 \mathrm{~kg} \mathrm{CO} 2$ eq., respectively), as the electricity consumption is the main contributor to the $\mathrm{CF}$. When using renewable electricity, the $\mathrm{CF}$ of $\mathrm{RO}$ is reduced to a level where it mitigates climate change like the other central softening methods. As electricity is only a minor component of the $\mathrm{CF}$ of the other processes, the positive effect of using renewable electricity on PR, WSR, IEX and DS is only minor. If the renewable electricity is produced by the drinking water 


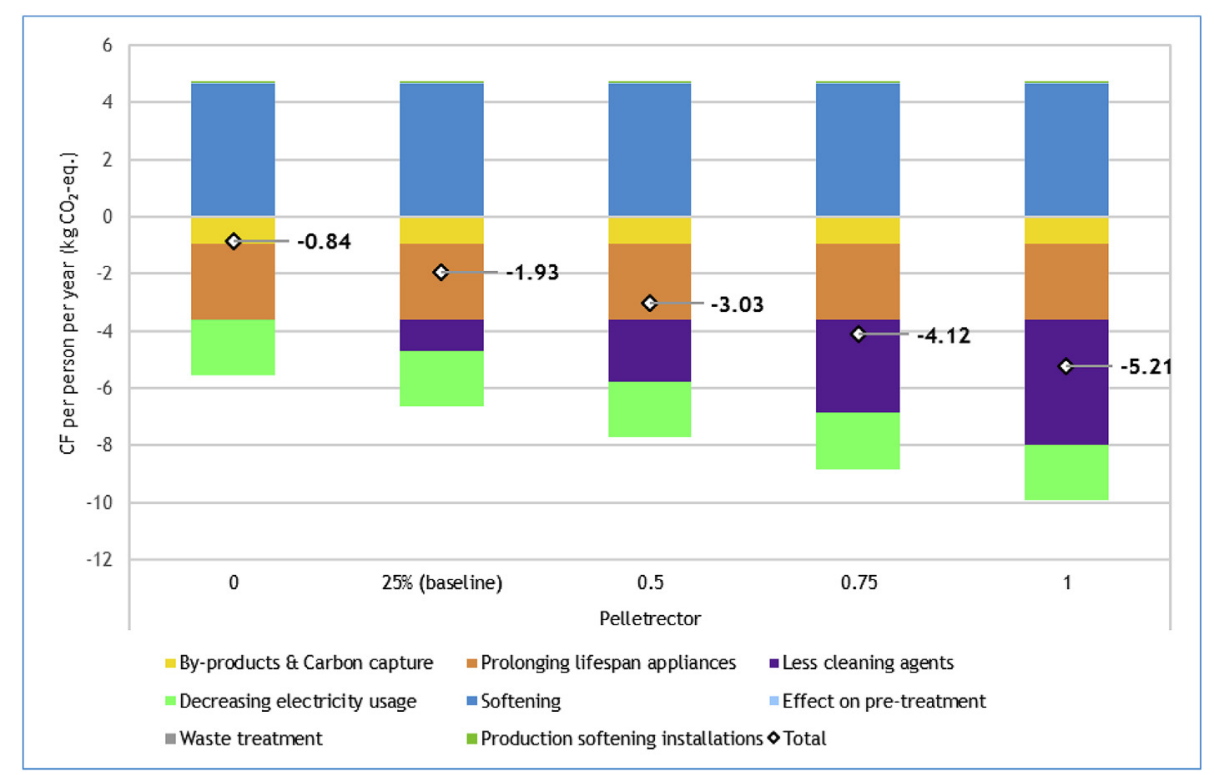

Fig. 3. Effect of percentage of consumers that use the correct lower amount of cleaning agents on the CF of central softening by PR.

company, NF remains the method with the lowest CF, but is then followed by RO as the best alternative.

\subsection{Effect on the carbon footprint of drinking water companies}

Evides softened $(-0.2 \mathrm{mmol} / \mathrm{L})$ about $180 \mathrm{Mm}^{3}$ water in the WSR Petrusplaat in 2017 (Evides, 2019). The chemicals used there for softening added about 5 ktonne $\mathrm{CO}_{2}$ eq. to the $\mathrm{CF}$ of Evides in that year. The beneficial effects of softening at households were, however, not considered. From the results presented here it can be shown that these amount to about -9 ktonne $\mathrm{CO}_{2}$ eq. The net effect equals about $20 \%$ of the total CF, as determined according to the Greenhouse Gas Protocol, of the drinking water branch of Evides (Evides (2019).

Waternet softens about $95 \mathrm{Mm}^{3}$ water per year in PRs $(-1,0 \mathrm{mmol} / \mathrm{L})(\mathrm{VEWIN}, 2019)$. The chemicals used for softening add about 4 ktonne $\mathrm{CO}_{2}$ eq. to the $\mathrm{CF}$ of Waternet. The beneficial consequences of softening at Waternet amount to about -13 ktonne $\mathrm{CO}_{2}$ eq. per year. The net effect is about $60 \%$ of the total $\mathrm{CF}$ of the drinking water branch of Waternet.

Based on these results, it becomes clear that some drinking water companies, such as Evides and Waternet, can significantly reduce the total carbon footprint of the complete supply chain by softening water.

In the Netherlands about $1200 \mathrm{Mm}^{3}$ of drinking water is produced per year (VEWIN, 2019). About half of this is softened (Hofman et al., 2007), by removing approximately $1.3 \mathrm{mmol} / \mathrm{L} \mathrm{Ca}^{2+}$ on average (Siegers et al., 2002), to achieve water with a hardness of around $1.4-1.5 \mathrm{mmol} / \mathrm{L}$. Based on the presented CF of softening, for the Netherlands as a whole, the softening of drinking water is estimated to have a CF of approximately $-0.11 \mathrm{Mtonne} \mathrm{CO}_{2}$ eq. per year (environmental benefit). Most of the drinking water that can benefit from softening is already softened in the Netherlands, and only a few areas remain where softening to a hardness of about $1.4 \mathrm{mmol} / \mathrm{L}$ can be beneficial. Softening in those areas and/or to a hardness of $1.0 \mathrm{mmol} / \mathrm{L}$ has the potential to further mitigate climate change, especially if coupled to behavioural changes at the household level. The largest environmental benefits can, however, be obtained in countries were hard drinking water is currently not softened at a central level.

\section{Conclusions}

The CF of softening, e.g. as this is currently done by Dutch drinking water companies, has been determined with a LCA, including effects at the consumers' homes. It is shown (i) that central softening from a hardness of 2.4 to $1.4 \mathrm{mmol} / \mathrm{L}$ mitigates climate change when the effects at the household level are taken into account, (ii) that a relevant contribution is due to carbon capture in calcite and subsequent redissolution of $\mathrm{CO}_{2}$ from the air into the softened water, and (iii) that the largest contribution is at the consumer, where further mitigation can be achieved if their use of cleaning agents is optimized.

The sensitivity analysis shows that selecting the central softening process with the lowest CF is complex, as realistic changes in the carbon footprint caused by the source of the used $\mathrm{NaOH}$, electricity and the effect of carbon capture in calcite by-products can easily change which method has the lowest CF. This means that local circumstances are likely to be the deciding factor in which central softening process is preferable from the point of view of the CF.

The net effect of drinking water softening on the carbon footprint of drinking water companies is substantial; about $20-60 \%$ of the carbon footprint for Evides and Waternet, respectively. For the Netherlands as a whole, the net effect is estimated at -0.11 Mtonne $\mathrm{CO}_{2}$ eq. per year. Drinking water softening in areas with medium to high water hardness thus has the potential to significantly reduce the carbon footprint of drinking water companies.

\section{Recommendations and future perspective}

With respect to the results for RO and NF: these softening methods are applied in case other issues also need to be addressed, such as removal of micro-organisms, colour, organic matter and/or organic micro-pollutants. The results for RO and NF presented here basically allocate all impacts of RO and NF to softening and such other benefits are thereby ' $\mathrm{C} F$ free'. The results of this study should, therefore, not be interpreted as a discouragement to implementing RO or NF in case such other issues are present, solely to reduce the $\mathrm{CF}$ of softening. A system perspective is key; the choice for a softening method should always fit the situation, as clean and healthy 
drinking water is of course the most important result.

The main source of uncertainty in the CF of softening as presented here is the percentage of consumers that use the optimum amount of cleaning agents. We have shown that the $\mathrm{CF}$ for central softening decreases by $4.4 \mathrm{~kg} \mathrm{CO} 2$ eq. per person per year from $0 \%$ to $100 \%$ of the consumers doing so. This is three times higher than the net CF effect as determined here for PR in the main LCA (Fig. 2). The potential difference (and the uncertainty) in results is even larger for decentral softening. More research could help gain clearer insight into potential gains at the household level, and especially the factors which stimulate consumers to change their behaviour and thereby help reduce the CF over the whole supply chain.

The CF of energy, steel, concrete, chemicals, household appliances, cleaning agents etc. is expected to continually decrease in the coming decades, as for 2050 the EU decided to achieve a $80-95 \%$ reduction in CF and is now pushing for a net zero CF. All contributions to the CF of softening of drinking water by PR, WSR, RO, NF and IEX (including DS) will decrease because of this, except carbon capture. As this component becomes the main contributor to the CF of PR and WSR, it will become necessary to investigate and quantify it in more detail, so that carbon benefits can be reported accordingly. Installations last for many decades; PR and WSR installed in the seventies and eighties are still in operation. Coupled to campaigns aimed at raising consumer awareness, the implementation of central softening is expected to have a continuously decreasing, net climate-mitigating, $\mathrm{CF}$.

\section{CRediT authorship contribution statement}

Mart Beeftink: Writing - original draft, Writing - review \& editing, Conceptualization, Project administration, Investigation, Data curation, Methodology, Visualization. Bas Hofs: Writing original draft, Writing - review \& editing, Conceptualization, Project administration, Investigation, Methodology, Visualization, Supervision, Funding acquisition. Onno Kramer: Writing - review \& editing, Conceptualization. Ingrid Odegard: Writing - original draft, Methodology, Conceptualization, Project administration, Supervision. Albert van der Wal: Writing - review \& editing, Funding acquisition.

\section{Declaration of competing interest}

The authors declare that they have no known competing financial interests or personal relationships that could have appeared to influence the work reported in this paper.

\section{Acknowledgements}

The authors would like to thank the members of the DutchFlemish Drinking Water Technologists Network for their comments.

\section{Appendix A. Supplementary data}

Supplementary data to this article can be found online at https://doi.org/10.1016/j.jclepro.2020.123925.

\section{References}

Abeliotis, K., Candan, C., Amberg, C., Ferri, A., Osset, M., Owens, J., Stamminger, R. 2015. Impact of water hardness on consumer's perception of laundry washing results in five European countries. Int. J. Consum. Stud. 39 (1), 60-66. https:// doi.org/10.1111/ijcs.12149.

AquaCell, 2019. https://www.aquacell-waterontharder.nl/. Accessed on 2019-11-11.

AquaMinerals, 2019. Personal communication with de Jong, A.L environment and sustainability manager.
Barrios, R., Siebel, M., van der Helm, A., Bosklopper, K., Gijzen, H., 2008. Environmental and financial life cycle impact assessment of drinking water production at Waternet. J. Clean. Prod. 16, 471-476. https://doi.org/10.1016/ j.jclepro.2006.07.052.

Bisschops, I., Zeeman, G., 2018. Theoretische analyse van de zuurstofvraag. Stichting Toegepast Onderzoek Waterbeheer, Amersfoort. ISBN 978.90.5773.807.4. https://www.stowa.nl/sites/default/files/assets/PUBLICATIES/Publicaties\% 202018/STOWA\%202018-41\%20zuurstofanalyse.pdf. Accessed on 2020-02-11.

Bonton, A., Bouchard, C., Barbeau, B., Jedrzejak, S., 2012. Comparative life cycle assessment of water treatment plants. Desalination 284, 42-54. https://doi.org/ 10.1016/j.desal.2011.08.035.

van der Bruggen, B., Goossens, H., Everard, P.A., Stemgée, K., Rogge, W., 2009. Costbenefit analysis of central softening for production of drinking water. J. Environ. Manag. 91, 541-549. https://doi.org/10.1016/j.jenvman.2009.09.024.

Burhenne, L., Giacomin, C., Follett, T., Ritchie, J., McCahill, J.S.J., Mérida, W., 2017. Characterization of reactive $\mathrm{CaCO}_{3}$ crystallization in a fluidized bed reactor as a central process of direct air capture. Journal of Environmental Chemical Engineering 5 (6), 5968-5977. https://doi.org/10.1016/j.jece.2017.10.047.

Dits, J.S., 1995. Raw-water softening in the Biesbosch reservoirs. J. Water Supply Res. Technol. - Aqua 44 (1), 92-96.

Drinkwaterbesluit, 2018. https://wetten.overheid.nl/BWBR0030111/2018-07-01. Accessed on 2019-11-11.

EEA, 2018. Water use in Europe - quantity and quality face big challenges. https:// www.eea.europa.eu/signals/signals-2018-content-list/articles/water-use-ineurope-2014. Accessed on 2020-03-06

Evides, 2019. Unpublished Data.

Godskesen, B., Hauschild, M., Rygaard, M., Zambrano, K., Albrechtsen, H.-J., 2012. Life cycle assessment of central softening of very hard drinking water. J. Environ. Manag. 105, 83-89. https://doi.org/10.1016/j.jenvman.2012.03.030.

Graveland, A., van Dijk, J.C., de Moel, P.J., Oomen, H.C.J., 1983. Developments in water softening by means of pellet reactors. Journal of the American Association of Water Works 75 (12), 619-625. https://doi.org/10.1002/j.15518833.1983.tb05247.x.

Gruber, N., Sarmiento, J.L., Stocker, T.F., 1996. An improved method for detecting anthropogenic $\mathrm{CO}_{2}$ in the oceans. Global Biogeochem. Cycles 10 (4), 809-837. https://doi.org/10.1029/96GB01608.

Gruber, N., Clement, D., Carter, B.R., Feely, R.A., van Heuven, S., Hoppema, M., Ishii, M., Key, R.M., Kozyr, A., Lauvset, S.K., Monaco, C.L., Mathis, J.T., Murata, A. Olsen, A., Perez, F.F., Sabine, C.L., Tanhau, T., Wanninkhof, R., 2019. The oceanic sink for anthropogenic $\mathrm{CO}_{2}$ from 1994 to 2007. Science 363, 6432. https:// doi.org/10.1126/science.aau5153, 1193-1199.

GWRC, 2007. Drinking Water Hardness: Reasons and Criteria for Softening and Conditioning of Drinking Water. London. ISBN 987-90-77622-18-6.

van der Hoek, J.P., Struker, A., de Danschutter, J.E.M., 2017. Amsterdam as a sustainable European metropolis: integration of water, energy and material flows. Urban Water J. 14 (1), 61-68. https://doi.org/10.1080/1573062X.2015.1076858.

Hofman, J., van der Hoek, J.P., Nederlof, M., Groenendijk, M., 2007. Twenty years of experience with central softening in The Netherlands: water quality, environmental benefits, and costs. Water 21, 21-24. February.

Hofman-Caris, R., Huiting, H., Snip, L., van den Brand, T., Palmen, L., 2016. Ontharding 2.0 bij Waternet; productielocatie leiduin. KWR, BTO2016.001a. https://edepot.wur.nl/424142.

Hoslett, J., Massara, T.M., Malamis, S., Ahmad, D., Van den Boogaert, I., Katsou, E., Ahmad, B., Ghazal, H., Simons, S., Wrobel, L., Jouhara, H., 2018. Surface water filtration using granular media and membranes: a review. Sci. Total Environ. 639, 1268-1282. https://doi.org/10.1016/j.scitotenv.2018.05.247.

van den Hoven, ThJ.J., van Eekeren, M.W.M., 1988. Optimal Composition of Drinking Water. KIWA Mededeling 100. KIWA Water Research, Nieuwegein, the Netherlands.

Mohapatra, P.K., Siebel, M.A., Gijzen, H.J., van der Hoek, J.P., Groot, C.A., 2002. Improving eco-efficiency of Amsterdam water supply: a LCA approach. J. Water Supply Res. Technol. - Aqua 51 (4), 217-227. https://doi.org/10.2166/ aqua.2002.0019.

Mulder, M., 2014. Minder Hard - Meer Profijt. Stichting Toegepast Onderzoek Waterbeheer. STOWA, Amersfoort, 2014-46. https:/www.stowa.nl/sites/ default/files/assets/PUBLICATIES/Publicaties\%202014/STOWA\%202014-46.pdf.

Regueira, J.M., 2000. Determining the Optimal Hardness Level for the Least Environmental Impact in the Production and Consumption of Drinking Water. MSc Thesis Report SEE -110. UNESCO-IHE Institute for Water Education, Delft, the Netherlands.

RHDHV, 2019. Personal Communication with Bakker. M. (senior expert cost estimation and risk management water sector).

de Ridder, D., Jeworrek, A., Hogendoorn, A., 2019. Hardheidverlaging GOSD. Voorstudie ontharding Ouddorp en Haamstede (Unpublished internal report, Evides).

Sabeen, A.H., Noor, Z.Z., Ngadi, N., Almuraisy, S., Raheem, A.B., 2018. Quantification of environmental impacts of domestic wastewater treatment using life cycle assessment: a review. J. Clean. Prod. 190, 221-233. https://doi.org/10.1016/ j.jclepro.2018.04.053.

Schetters, M.J.A., van der Hoek, J.P., Kramer, O.J.I., Kors, L.J., Palmen, L.J., Hofs, B., Koppers, H., 2015. Circular economy in drinking water treatment: reuse of ground pellets as seeding material in the pellet softening process. Water Sci. Technol. 71 (4), 479-486. https://doi.org/10.2166/wst.2014.494.

Siegers, W., 2002. Overzicht Van Korrelreactoren in Nederland. KWR. KWR 2002.087. 
Sombekke, H.D.M., Voorhoeve, D.K., Hiemstra, P., 1997. Environmental impact assessment of groundwater treatment with nanofiltration. Desalination 113 (2-3), 293-296. https://doi.org/10.1016/S0011-9164(97)00144-6.

Tang, C., Merks, C.W.A.M., Albrechtsen, H.-J., 2019. Water softeners add comfort and consume water - comparison of selected centralised and decentralised softening techniques. Water Supply 19 (7), 2088-2097. https://doi.org/10.2166/ ws.2019.088.

Tapia, M., Siebel, M.A., van der Helm, A.W.C., Baars, E.T., Gijzen, H.T., 2008. Environmental, financial and quality assessment of drinking water processes at Waternet. J. Clean. Prod. 16, 401-409. https://doi.org/10.1016/ j.jclepro.2006.07.053.

VEWIN, 2017. Watergebruik thuis 2016. https://www.vewin.nl/ SiteCollectionDocuments/Publicaties/Cijfers/Watergebruik-Thuis-2016.pdf. Accessed on 2020-06-26.
VEWIN, 2019. Drinking water fact sheet, 2019. https://www.vewin.nl/ SiteCollectionDocuments/Publicaties/Drinking\%20water\%20fact\%20sheet\% 202019.pdf. Accessed on 2019-11-21.

Waternet, 2019. Personal Communication with Klaversma. E. (LCA specialist). WHO, 2017. Guidelines for Drinking-Water Quality, fourth ed. incorporating the first addendum. https://www.who.int/water_sanitation_health/publications/ drinking-water-quality-guidelines-4-including-1st-addendum/en/ Accessed on 2020-03-06.

Wooley, R.J., Millero, F.J., Wanninkhof, R., 2015. Rapid anthropogenic changes in CO and $\mathrm{pH}$ in the Atlantic Ocean: 2003-2014. Global Biogeochem. Cycles 30 (1), 70-90. https://doi.org/10.1002/2015GB005248.

WQRF, 2011. Softened Water Benefits Study. Water Quality Research Foundation, Lisle, Illinois. https://www.wqa.org/Portals/0/WQRF/ResearchStudy BenefitsOfSoftenedWater_ExecSummary.pdf. Accessed on 2020-02-11. 